\title{
UMA VISÃO CRÍTICA DAS POLÍTICAS DE DESCRIMINALIZAÇÃO E DE PATOLOGIZAÇÃO DO USUÁRIO DE DROGAS
}

\author{
Ari Bassi Nascimento
}

\begin{abstract}
RESUMO. Concorda-se que conseqüências da manufatura, síntese, tráfico e uso de drogas resultem em ameaça ao bem-estar coletivo. Todavia, o Estado dispõe de políticas públicas que só simbolicamente previnem a materialização dessa ameaça. É possível identificar duas políticas públicas com vistas a atenuar problemas derivados do uso de drogas. A primeira fundamenta suas ações sobre os princípios do estatuto punitivo brasileiro, perpetuando uma afronta ao princípio da lesividade, já que constitucionalmente a autolesão não tipifica conduta criminosa. A segunda ampara-se sobre uma abordagem de descriminalização, mas patologiza o usuário. O objeto de ação das duas políticas é a conduta ou o usuário e ambas se fundamentam sobre o viés filosófico da retributividade ou da máxima de que punição resulta em educação; tratando-o como criminoso ou como doente, as consequiências dessas políticas resultam em robustez da economia da droga e iatrogenia do mal a ser tratado.
\end{abstract}

Palavras-chave: políticas públicas, economia da droga, criminalização.

\section{PUBLIC POLICIES' ATTEMPTS TO REDUCE THE DRUGS USE EITHER BY CRIMINATING OR TREATING THE DRUG USER}

\begin{abstract}
If the welfare state is threatened either by synthesis, manufacture, traffic or drugs use, it is expected that State formulates public policies to prevent injuries to the common good In layman terms, activities related to the use abusive of drugs are able to threaten that common good. So, public policies should prevent the materialization of such threat. Two sorts of public policies intending to attenuate the social problems raised by drug abuse can be identified. The first is supported by a punitive philosophy which approaches the problem by criminating the drug user. By using penal rights, it does force users to face the consequences of the law, such as prison. The second seeks protection in a de-criminalization approach, but pathologizes the user. The object of action of the two politics is the conduct or the user, and both are based in the philosophical belief of compensation or in the rule of conduct that punishment results in education. Be the user treated as a criminal or as a sick individual, the consequences of those politics result in increase of the drug economy and iatrogenicity of the illness to be treated.
\end{abstract}

Key words: Public policies, drug economy, criminalization.

\section{O OBJETO DAS POLÍTICAS PÚBLICAS PERTINENTES AO CONSUMO DE DROGAS}

O uso abusivo de drogas constitui um problema social. Há que se entender essa afirmação como verdadeira, mas de forma muito restritiva. Afinal, o que constitui um problema social são os prejuízos econômicos (no sentido lato) resultantes do abuso de drogas. Esses prejuízos devem decorrer da interação indivíduo-droga e se materializam de formas diversas. Algumas se situam na esfera afetiva, outras nas esferas produtiva, educativa e da saúde ou nas relações sociais. Em qualquer uma dessas esferas de ação as relações dos indivíduos implicam em custos e em benefícios, daí por que quaisquer prejuízos nessas instâncias de ação resultam em prejuízos econômicos.

As tentativas de reduzir o impacto desses prejuízos não prosperaram. É possível que esse fracasso em prevenir as conseqüências desses prejuízos seja explicado em função de: (i) ausência de outro tipo de ação estatal que não seja o combate ao comportamento de consumir drogas pela via do direito penal; e (ii) o Estado põe em prática ações aparentemente divorciadas dos objetivos da sociedade em relação à economia de drogas, mostrando-se pouco eficaz em promover ações que diminuam essa economia e as conseqüências que são próprias dela.

* Doutor. Professor Associado do Departamento de Psicologia Geral e Análise do Comportamento da Universidade Estadual de Londrina. Bacharel em Direito. 
Quando algo - um conjunto de ações ou as conseqüências destas - revelam-se um problema social, comumente esse problema torna-se objeto de políticas cujas ações tendem a inibir, diminuir ou prevenir os fatores ditos causais. É por meio de políticas públicas que o Estado adquire legitimidade para agir sobre um grupo de indivíduos ou sobre um dado segmento da sociedade, na tentativa de implementar suas ações.

Não obstante, os problemas sociais derivados do uso abusivo de drogas e das atividades que tornam a droga objeto de tráfico parecem imunes aos efeitos das políticas públicas vigentes. Talvez seja apropriado afirmar que não há políticas públicas estruturadas e eficazes em reduzir aqueles problemas. De fato, o Estado apenas tateia entre ações que visam a punir ou tratar o consumidor de drogas. De forma objetiva, o que se aparenta como política pública vigente pertinente ao consumo de drogas visa unicamente ao combate da conduta de consumir drogas. Aparentemente, isso é apenas uma tautologia. Afinal, se houver uma política cujo objetivo for reduzir o consumo de drogas, mas cujas ações se concentrem na prevenção da conduta de usar drogas, então se está diante de uma circularidade. Há demonstrações de que não se afeta o comportamento do consumidor simplesmente retirando transitoriamente do contexto onde tal comportamento seja possível. Qualquer iniciativa fundamentada nessa pressuposição parte de lugar nenhum e reafirma a ineficiência estatal em levar a cabo a consecução de objetivos de suas políticas, se esses forem a redução do consumo de drogas.

Qualquer política pública que vise dar combate ao consumo de drogas de abuso requer algum tipo de filosofia que a norteie. Nesse aspecto, é mais fácil identificar filosofias que políticas. Podem ser identificadas duas filosofias. A primeira vê o usuário de drogas como criminoso; a segunda trata o usuário de drogas como doente, independentemente de a droga que consome ser reprovada legalmente ou aceita socialmente. A proposição de filosofias diferentes deriva de uma concepção analítica, privilegiando, inicialmente, uma separação entre as ontologias criminosa e patológica; todavia, uma concepção sintética dessas filosofias levará o leitor à compreensão de que as duas abordagens fundamentam-se num único princípio filosófico: o da punição.

A primeira filosofia deriva seu sistema normativo do estatuto punitivo do direito penal brasileiro. As conseqüências das ações orientadas segundo esta perspectiva são prisão, aplicação de medida de segurança ou transação penal. Essas consequiências serão discutidas a seguir e apresentadas como a primeira abordagem de combate à conduta de consumir drogas.

A segunda filosofia fundamenta-se nos pilares do modelo médico. O modelo médico é tradicional e tem poderes extraordinários sobre quase todas as camadas da sociedade. Assim, não é surpresa que o processo legislativo seja fortemente influenciado pelo lobby executado pelos defensores do modelo. Para o modelo, o usuário de drogas desenvolve adicção à substância e disso segue um estado patológico. Várias são as conseqüências da execução de ações sobre a conduta de consumir drogas nos termos deste modelo. Essas conseqüências serão descritas mais adiante, quando se tratar da segunda abordagem.

\section{A REDUÇÃO DO CONSUMO DE DROGAS VIA UMA POLÍTICA PÚBLICA CUJA FILOSOFIA SEJA A DE CRIMINALIZAR A CONDUTA DO USUÁRIO}

A primeira abordagem orienta as ações estatais quanto à conduta de consumir drogas. $\mathrm{O}$ aspecto material que justifica a ação do sistema estatal é a conduta de consumir drogas. Obviamente, requer-se que anteriormente o Estado tenha disposto normas proibindo aquela conduta. Geralmente, o comando legal penal visa regular uma parte da atividade humana, e o faz selecionando alguns comportamentos cujas consequiências sejam relevantes ao indivíduo ou ao meio social. O Estado, ao descrever uma ação típica, descreve um comportamento proibido. Para ser típico, esse comportamento revela o desvalor da ação e revela o desvalor do resultado. Daí o cabimento da pena quando se constatar a tipicidade material. A tipicidade material dá-se quando a conduta resulta em lesão a um bem jurídico relevante (Delmanto, Delmanto, Delmanto Junior \& Delmanto, 2002). Uma questão relevante aqui é demonstrar que a conduta de consumir drogas de abuso resulta em lesão a um bem jurídico e que este se situa na esfera do patrimônio jurídico de um sujeito diferente daquele que seja usuário de drogas. ${ }^{1}$

A discussão jurídica atual tende a classificar a conduta de consumir drogas como sinônima de autolesão que, como a tentativa de suicídio, não é crime e afastaria o principio da lesividade. Nos termos do princípio da lesividade, as condutas que serão incriminadas pela lei penal exigirão sujeito ativo e sujeito passivo (vítima), aquele que tenha sofrido abalo em seu patrimônio jurídico (Batista, 2001; Greco, 2005; Lopes, 1997; Rebêlo, 2000). Assim, mesmo que uma conduta formalmente atinja um bem jurídico, se a exteriorização dela não ultrapassar o âmbito do próprio autor não haverá crime. Já se sabe que as recomendações 
Em termos simples, a primeira abordagem combate problemas derivados do uso ilícitos de drogas de abuso ao criminalizar a conduta do usuário. A cominação de penas dependerá de vários fatores, mas a abordagem é baseada no sistema penal vigente e direciona suas ações a prevenir a sociedade dos problemas sociais derivados do consumo de drogas unicamente pela via da restrição do direito de ir e vir do infrator. A prisão em sua acepção ambígua - consiste em penalizar a conduta do usuário e ao local onde os direitos de ir e vir do usuário ficam restritos. Assim, a prisão decorre de uma ação de intervenção e de prevenção, simultaneamente. Entretanto, as concepções políticocriminais atuais questionam a validade de que, com a primeira ação, o Estado estabeleça para o usuário de drogas um preço justo a pagar por ter produzido lesão a um bem jurídico relevante resultante de sua conduta de consumir droga. Com a segunda ação, o Estado previne a sociedade da probabilidade de ter seu bem jurídico lesado futuramente pela repetição da conduta do usuário em consumir drogas. ${ }^{2}$

político-criminais atuais sugerem que não, conquanto a conduta de uso possa ser sinônima de autolesão, pois ainda que seja típica uma atitude, se ela não causar uma lesão relevante ao patrimônio jurídico do sujeito passivo não poderá ser incriminada penalmente. Mas a questão de fato interessante, se não intrigante, é se o uso abusivo de substâncias ditas entorpecentes deve ou não ser coibido penalmente. O uso do termo "entorpecente" é fatal. Nitidamente predispõe o observador a avaliações cautelosas quanto ao "poder de discernimento" do usuário. É óbvio que não se investiga a historicidade dos contextos em que o uso do termo resultou de uma prática verbal útil para uma certa comunidade. Todavia, o uso fortalecido do termo favoreceu o desenvolvimento de concepções que apontam para prejuízos de juízo crítico do sujeito que faz uso de drogas entorpecentes. Noutros termos, efeitos históricos, contextuais e farmacológicos dessas drogas parecem ter o poder de deixar o indivíduo pouco susceptível às contingências de ordem. Daí a prevenção inclusive criminal, já que vigente o art. 16 da Lei 6.368/76 - contra o uso dessas drogas. A questão, entretanto, é bem mais complexa e seria proveitoso se o adjetivo "entorpecente" fosse abandonado. Afinal, se a droga for aceita socialmente, pouco - se não nada - se faz quanto à prevenção da conduta que leva ao seu consumo. Aliás, já há defesa no sentido de que inclusive o art. 16 da referida lei seja inconstitucional, dado que o poder de definir qual substância seja entorpecente cabe à ANVISA, e não à norma contida no dispositivo, que é entendida como uma norma penal em branco. O que se defende é que a inclusão de novas substâncias (criminalização) ou exclusão (descriminalização) dar-se-á sem a participação do poder competente para legislar em matéria penal (Copetti, 2000).

2 Para uma visão crítica destes dois pontos, o leitor deve consultar a nota de rodapé anterior.
As ações estatais orientadas pela primeira abordagem têm-se caracterizado como as estratégias pelas quais o Estado intervém na economia da droga. Todavia, o uso efetivo dessa abordagem provoca uma hipertrofia do sistema repressivo. Essa hipertrofia, além de não resultar em benefícios para a sociedade, ainda torna os praticantes daquela economia muito mais eficientes. Isso porque quanto mais o Estado aja repressivamente sobre o usuário, mais ele favorecerá o aperfeiçoamento dos fatores macro e microeconômicos da economia da droga. Em parte isso ocorre porque as ações estatais resultam em um tipo de pressão seletiva sobre os praticantes daquela economia.

A consequiência de curto-prazo de uma ação repressiva massiva sobre a conduta do usuário será redução do custo (custo lato) da droga para a sociedade. Essa redução dar-se-á tanto em termos de número de usuários como em termos de quantidades consumidas. Infelizmente, a sociedade não se beneficiará desses resultados, porquanto junto a eles seguir-se-á o aparecimento de fornecedores de menor potencialidade econômica, cujas ações eram suprimidas pelas leis econômicas do mercado das drogas. Eles ofertarão drogas mais baratas, de forma local e segura ,e não serão alvos - por certo tempo - das ações repressivas estatais nem de ações retaliatórias de grandes fornecedores. Já a médio-prazo haverá mais droga disponível por um preço menor, com probabilidade de se aumentar o número de consumidores (Kopp, 1998). O que se pode dizer é que ações orientadas pela primeira abordagem não são eficientes para se prevenir que o custo social marginal da droga aumente.

\section{UMA POLÍTICA PÚBLICA QUE AO DESCRIMINALIZAR A CONDUTA DE USAR DROGAS PATOLOGIZA O USUÁRIO PODE SER EFICAZ?}

A segunda abordagem intervém sobre o domínio do uso de drogas de forma diferente. Em vez de criminalizar a conduta de consumir certa quantidade de um tipo particular de droga, as ações norteadas segundo os termos dessa abordagem visam rotular o usuário como alguém que requer cuidados, geralmente de ordem médica e/ou psicológica. Nisso não há muita novidade. A novidade será a adoção de uma estratégia que vise descriminalizar a conduta de consumir drogas por um lado e patologizar o usuário, por outro.

A estratégia de descriminalização apresenta precedentes. Primeiro, há casos em que a conduta de consumir um tipo particular de droga materializa 
claramente uma conduta tipificada, portanto ilícita. Entretanto, mesmo em casos assim o Estado abre mão das suas prerrogativas de aplicar pena de prisão e aplica ao usuário o que é conhecido como medida de segurança, sem, contudo, abrir mão de exercer o poder de jus puniendi; e ao exercer sua faculdade de punir, o Estado o fará somente se comprovados os elementos do tipo (material ou formal), a antijuridicidade e a culpabilidade. Segundo, há ainda outros casos em que as polícias brasileiras orientam-se pela não-prisão do usuário quando se demonstra que o tipo e a quantidade de drogas parecem não ofensivos ao usuário e à sociedade, mas destinados apenas ao uso eventual do usuário. Terceiro, um indivíduo - dependendo da circunstância em que tenha sido flagrado portando ou consumindo um dado tipo e quantidade de drogas poderá ser encaminhado ao Poder Judiciário, e caso sua conduta tipifique os termos do artigo 16 da Lei 6.368, de $1976^{3}$, caberá ao Estado aplicar-lhe pena de detenção não inferior a seis meses e não superior a dois anos. Como a pena cominada ao tipo penal é de detenção, e não superior a dois anos, a competência para julgar a ação penal será do juizado especial criminal, obedecendo ao rito processual especificado pela lei 9.099 , de $1995^{4}$. Em fórum de juizado, caberá ao Ministério Público, em fase preliminar da ação penal, propor a aplicação imediata de pena de multa ou pena restritiva de direitos.

Esses três pontos dão mostra de que o Poder Legislativo tem produzido leis mais flexíveis quanto à gravidade penal da conduta de consumir dada quantidade de um tipo de droga. Adicionalmente, as interpretações dadas aos estatutos legais que abordam o consumo de droga, tendo este como objeto de interesse principal, revelam que a dialética das partes de uma lide junto ao Poder Judiciário resulta em um paradigma que se volta à não-penalização da conduta de consumir drogas. Entretanto, as iniciativas derivadas dos poderes Legislativo e Judiciário somente fomentam um campo para as discussões do que pareça ser a filosofia que norteará as ações estatais pertinentes a como agir sobre os problemas sociais derivados do consumo de drogas.

Essa filosofia já se aparenta claramente delimitada. Ela tem cara de ação descriminalizante

\footnotetext{
Lei $\mathrm{n}^{\circ}$. 6.368, de 21 de setembro de 1976. Dispõe sobre medidas de prevenção e repressão ao tráfico ilícito e uso indevido de substâncias entorpecentes ou que determinem dependência física ou psíquica, e dá outras providências.

4 Lei $\mathrm{n}^{\circ}$. 9.099, de 26 de setembro de 1995. Dispõe sobre os Juizados Especiais Cíveis e Criminais e dá outras providências.
}

somente post factum. Quer-se dizer com isso que a conduta de usar droga ou substância dita ilícita, ou que cause dependência física ou psíquica (termos absolutamente impróprios, porém constantes de lei), tipificará crime de uso e, quase sempre, implicará a participação do Ministério Público na proposição de ação penal contra o usuário. Nestes termos, o tratamento legal dispensado ao usuário de drogas é o da criminalização da conduta de uso; porém, o que ocorre a partir do ato do Ministério Público de oferecer a denúncia de ação penal contra o usuário de droga é extraordinário. Com esse ato abrem-se duas possibilidades: uma da descriminalização da conduta de uso e a outra da patologização do usuário.

No estágio atual da legislação, a descriminalização só será possível após a criminalização da conduta de uso. Está claro que isso não caracteriza qualquer forma de descriminalização, mas uma decorrência da ação penal. A descriminalização deve preceder a qualquer ação do Ministério Público, de forma a retirar deste a titularidade para propor ação penal contra o usuário de droga, ou não será descriminalização. Mas isso implica, como se discute abaixo, em outras mudanças na legislação que cuida do assunto. A outra possibilidade é a da patologização do indivíduo. Os cinco parágrafos do artigo 12 , da Lei 10.409 , de $2002^{5}$, apontam que ao dependente deve ser dispensado tratamento multiprofissional, cabendo ao Ministério da Saúde regulamentar as ações que visem à redução de danos sociais e à saúde. Enquanto empresas privadas que contam com programas de reinserção no mercado de trabalho de adictos aos efeitos de drogas estão aptas a receber benefícios ainda a ser definidos pela União e seus entes, hospitais gerais e psiquiátricos enviarão ao Conselho Nacional Antidrogas - CONAD, a cada mês, mapa estatístico dos casos atendidos no mês anterior contendo o código da doença segundo especificações da OMS, omitindo o nome do atendido.

Não obstante, não importando que decorrer desse campo de discussões, as orientações futuras implicarão em mais instrumentos normativos que regularão as relações de indivíduos relativas ao uso de drogas. Se essas orientações, ao regular essas relações, adotarem o princípio da descriminalização da conduta de consumir drogas, elas o farão com muita restritividade; e, ainda assim, abrirão caminho para se

\footnotetext{
Lei $n^{\circ}$. 10.409, de 11 de janeiro de 2002. Dispõe sobre a prevenção, o tratamento, a fiscalização, o controle e repressão à produção, ao uso e ao tráfico ilícitos de produtos, substâncias ou drogas ilícitas que causem dependência física ou psíquica, assim elencados pelo Ministério da Saúde, e dá outras providências.
} 
implantar a segunda abordagem. Em parte porque as ações de criminalizar ou de descriminalizar - adotadas exclusivamente uma em relação à outra - parecem mostrar-se ineficazes; em parte também porque não se podem excluir os componentes médico-farmacológicos e psicobiológicos intrínsecos à conduta de consumir drogas. O problema aqui é considerar em que medida se aplicarão os fundamentos das duas abordagens, de maneira que, ao se orientar pelos princípios de uma abordagem, não se excluam os princípios da outra.

Vistas sob essas perspectivas, as ações estatais que visem prevenir o consumo de drogas são estáticas por um lado e dinâmicas por outro. Elas são estáticas porque o Estado, mediante suas ações ou suas políticas públicas, não desloca o objeto da intervenção da conduta do usuário ou do usuário propriamente dito. Ainda que as ações estatais se modifiquem, o alvo delas continua sendo a conduta do usuário (no sentido penal) ou o próprio usuário. A visão de que a economia da droga e os problemas derivados dela possam ser combatidos concentrando ações sobre a conduta ou sobre o usuário é extremamente limitada. Sejam as ações criminalizantes, descriminalizantes ou patologizadoras do usuário - que constituem a dinâmica das ações estatais -, elas continuam presas ao último elo da cadeia da economia da droga. Assim, mesmo que essas ações apareçam num domínio de continuidade evolutiva, revelando o dinamismo com o qual a sociedade encara os problemas sociais derivados do abuso de drogas, os méritos desse dinamismo serão mitigados por conta de essas ações não se deslocarem para além da conduta ou do próprio usuário.

\section{UMA SÍNTESE SOBRE AS POLÍTICAS PÚBLICAS QUE VISAM COMBATER O USO DE DROGAS COM USO DE MODELOS PENAL E MÉDICO}

Uma política pública de combate às drogas orientada por uma filosofia que trate o usuário como criminoso materializa a máxima de que a punição resulta em educação. A outra política, norteada pela filosofia de que usuários de drogas demonstram padrões patológicos de condutas resulta também em um modelo de intervenção no sentido de dispensar tratamentos ao usuário. Os tratamentos derivam de conhecimentos e práticas de campos de conhecimento diversos e podem ser agrupados em dois modelos: médico-farmacológico e psicossosociocultural. Sob quaisquer perspectivas bem animadoras, a eficácia desses modelos juntos sobre o tratamento da adicção aos efeitos de drogas não é superior a dez por cento (Milby, 1988).

A abordagem que trata o usuário de droga como criminoso alega que drogas são fontes de financiamento político, de corrupção, de geração de riquezas e do aumento do custo social marginal. Tautologicamente, as drogas são fontes de crimes. A abordagem que trata a conduta do usuário como patológica representa um erro duplo da sociedade. O primeiro é que negligencia em proceder via prevenção optando pela via da intervenção; o segundo, que ignora que a via da intervenção seja fonte de iatrogenia do comportamento de adicção aos efeitos de drogas.

Por fim, se por um lado o espelho da droga é a conduta do usuário de drogas, por outro lado, o tratamento é a vitrine da sociedade que se vê refletida nas preocupações do Estado, paladino da manutenção de bens jurídicos sociais como ordem, segurança e direitos à propriedade. A "eliminação" do usuário pode até permitir ao Estado a garantia desses bens. Todavia, ao agir assim, sociedade e Estado somente agravarão as resultantes da relação havida entre drogas e usuário.

Será preciso reorientar as concepções da sociedade e as ações do Estado a outras direções. Isso implica em mudar o foco da atenção. A conduta do usuário interessará a quaisquer políticas somente se constituir aquilo que a farmacologia comportamental entende ser seu objeto de estudo. Qual seja, a relação entre drogas e usuário será relevante quando se constituir em um conjunto de relações comportamentais, caracterizado pelos comportamentos de procurar, adquirir e consumir drogas cujas consequiências inviabilizem parcial ou totalmente a disponibilidade do indivíduo como recurso produtivo ou, alternativamente, levem o indivíduo a atividades dilapidadoras, resultando em prejuízos de ordem econômica, produtiva, legal, afetiva e moral.

Se esses indicativos ausentarem da relação indivíduo-droga, sociedade e Estado deverão olhar em direção (1) aos fatores que concorrem para a disponibilidade de drogas, (2) às mudanças culturais que autorizam dispor sobre a proibição ou aceitação social da droga, (3) a uma modernização da terminologia, cuidando-se de rótulos impróprios para descrever as relações entre usuário e drogas e evitar a classificação de drogas como lícitas ou ilícitas, já que esses rótulos não cabem a elas, mas às atividades humanas, (4) à economia da droga como uma atividade de comércio de penetração social ampla e (5) olhar para as consequiências de suas atividades interventivas que, ainda que indesejável, resultam em 
aumento do consumo de drogas, aumento do lucro dos traficantes drogas, aumento da corrupção dos agentes estatais envolvidos na operacionalização dessas políticas e aumento do custo social marginal da droga, que tem sido e será pago - é claro - pela sociedade. Ao atentar a esses cinco pontos, sociedade e Estado envidariam ações eficazes para reduzir os danos decorrentes do consumo de drogas. Ao insistir em intervenções sobre a conduta do usuário, ora o tratando como criminoso, ora o tratando como doente, esses dois entes não irão além de perpetrar práticas cujas conseqüências estão descritas em 1 e 5.

\section{REFERÊNCIAS}

Batista, N. (2001) Introdução crítica ao direito penal brasileiro. ( $5^{\mathrm{a}}$ ed.). Rio de Janeiro: Revan.

Copetti, A. (2000) Direito penal e estado democrático de direito. Porto Alegre: Livraria do Advogado.
Delmanto, C., Delmanto, R., Delmanto Junior, R. \& Delmanto, F. M. A. (2002, $6^{\mathrm{a}}$ ed. atualizada e ampliada). Código penal comentado. Rio de Janeiro: Renovar.

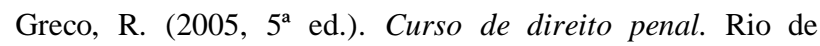
Janeiro: Impetus.

Kopp, P. (1998). A economia da droga. (M. E. O. O. Assumpção, Trad.). Bauru: EDUSC.

Lopes, M. L. (1997). Princípio da Insignificância no Direito Penal. RT.

Milby, J. B. (1988). A dependência de drogas e seu tratamento. (S. M. Carvalho, Trad.). São Paulo: Editora da Universidade de São Paulo.

Rebêlo, J. H. G. (2000). Princípio da insignificância: interpretação jurisprudencial. Belo Horizonte: Del Rey.

Recebido em 10/06/2005 Aceito em 27/10/2005

Endereço para correspondência: Ari Bassi Nascimento. Departamento de Psicologia Geral e Análise do Comportamento, Centro de Ciências Biológicas, Universidade Estadual de Londrina, Campus Universitário, Caixa Postal 6001, CEP 86051-990, Londrina-PR. E-mail: bassi@uel.br 